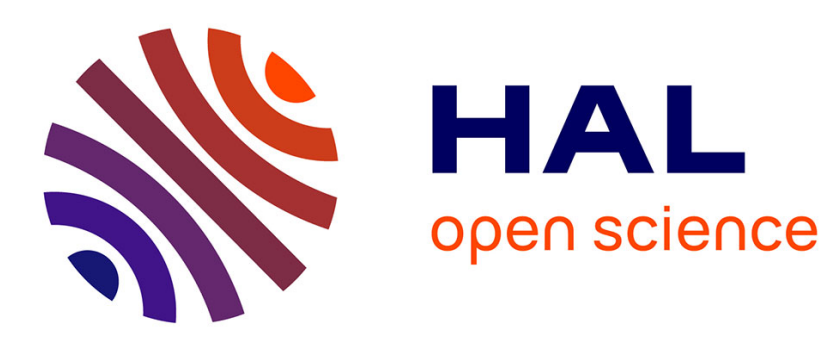

\title{
Genetic variation in Pinus taeda wood properties predicted using non-destructive techniques
}

Isik, Christian Mora, Laurence Schimleck

\section{To cite this version:}

Isik, Christian Mora, Laurence Schimleck. Genetic variation in Pinus taeda wood properties predicted using non-destructive techniques. Annals of Forest Science, 2011, 68 (2), pp.283-293. 10.1007/s13595011-0035-9 . hal-00930770

\section{HAL Id: hal-00930770 \\ https://hal.science/hal-00930770}

Submitted on 1 Jan 2011

HAL is a multi-disciplinary open access archive for the deposit and dissemination of scientific research documents, whether they are published or not. The documents may come from teaching and research institutions in France or abroad, or from public or private research centers.
L'archive ouverte pluridisciplinaire HAL, est destinée au dépôt et à la diffusion de documents scientifiques de niveau recherche, publiés ou non, émanant des établissements d'enseignement et de recherche français ou étrangers, des laboratoires publics ou privés. 


\title{
Genetic variation in Pinus taeda wood properties predicted using non-destructive techniques
}

\author{
Fikret Isik • Christian R. Mora • Laurence R. Schimleck
}

Received: 18 March 2010 /Accepted: 10 July 2010/Published online: 25 February 2011

(C) INRA and Springer Science+Business Media B.V. 2011

\begin{abstract}
- Background Tree breeders have been reluctant to include wood traits in tree improvement programs owing to logistic difficulties and the cost associated with the assessing the traits. - Methods We aimed to evaluate the efficiency of two nondestructive techniques for genetic parameters estimation in three diallel test series of loblolly pine (Pinus taeda L.). The traits were measured by acoustics (velocity, stiffness) and predicted by calibration models based on near infrared (NIR) spectra (air-dry density, microfibril angle, modulus of elasticity, coarseness, wall thickness).

- Results Acoustic and NIR-predicted traits were not correlated with diameter based on 30 full-sib family means of each diallel series. Correlations between traits were in accordance with previous published results. Additive genetic variation was considerable for all traits. Specific combining ability variances were not significant. The traits predicted by acoustic and NIR methods had high narrow-sense individual tree and family mean heritability values. Individual tree narrow sense heritability ranged from 0.14 (tracheid coarseness) to 0.92 (air-dry density). As expected, family mean heritability values of most traits exceeded 0.80 .
\end{abstract}

Handling Editor: Luc Pâques

F. Isik $(\bowtie)$

Department of Forestry and Environmental Resources,

North Carolina State University,

Raleigh, NC 27695, USA

e-mail: fisik@ncsu.edu

C. R. Mora

Wood Properties Section, Bioforest S.A.,

P.O. Box 70-C, Concepción, Chile

L. R. Schimleck

Warnell School of Forestry and Natural Resources,

The University of Georgia,

Athens, GA 30602, USA
- Conclusions The high heritabilities suggest that acoustic and NIR-based methods can efficiently be used for screening loblolly pine progeny tests for surrogate wood traits. Such methods can save considerable resources in tree breeding programs that aim to improve wood quality.

Keywords Genetic variation · Pinus taeda - Wood properties $\cdot$ Non-destructive techniques $\cdot$ Heritability

\section{Introduction}

The southern United States is one of the largest timber producing regions in the world, being responsible for $58 \%$ of wood production within the USA and approximately $15 \%$ of the wood consumed globally (Wear and Greis 2002). Much of this production is based on plantationgrown loblolly pine (Pinus taeda $\mathrm{L}$.), a species native to the southeast that has been widely planted across the region. Efforts to improve the growth and yield of loblolly pine have been ongoing for over 50 years, with considerable research being conducted by industry/university cooperatives (Byram et al. 2005). Three cycles of loblolly pine improvement have been completed with large gains for growth-related traits. Orchards currently being established are predicted to have breeding values for growth rates which exceed the unimproved local sources by $30 \%$ ( $\mathrm{Li}$ et al. 1999a, b).

The combination of intensive management and genetically improved planting stock has produced improved growth rates, and subsequently merchantable size trees are available for harvest at younger ages (Atwood et al. 2002). While it is recognized that improvements in wood quality traits could also be achieved ( $\mathrm{Li}$ et al. 1999a), this has not been undertaken on a large scale, owing to the difficulty 
and cost associated with examining wood properties in a large number of trees. In addition, the collection of wood samples for analysis has often been destructive, which is undesirable when sampling young trees that potentially could be important in producing new progeny in a breeding program.

The development of rapid techniques that can be utilized to measure and predict wood properties of standing trees has made the inclusion of quality-related properties possible in breeding programs on a large scale. Several options now exist for the nondestructive assessment of wood properties, including acoustics (Wang et al. 2000; Chauhan et al. 2006), near infrared (NIR) spectroscopy (Kelley et al. 2004; Schimleck 2008), Resistograph (Isik and Li 2003) and SilviScan (Evans 1994, 2006).

Acoustic-estimated stiffness, for indirect measure of modulus of elasticity (MOE), has been used to determine genetic parameters in progeny tests. Kumar et al. (2002) and Lindström et al. (2004) reported high correlations between stress-wave speeds measured on standing trees and laboratory-measured MOE and modulus of rupture (MOR) in Pinus radiata. Time of flight as a surrogate for stiffness was evaluated for radiata pine, and non-significant additive and non-additive effects were estimated (Gapare et al. 2010). In these two studies high narrow-sense heritability $\left(h_{i}^{2}=0.46\right)$ and high clone mean repeatability $\left(H_{c}^{2}=0.95\right)$ were reported for stress wave measurements, suggesting that stress-wave speed can be a valuable tool for screening large numbers of trees in breeding populations for selection.

Genetic parameters for wood density, microfibril angle (MFA), stiffness, and tracheid dimensions in radiata pine have also been determined nondestructively based on wood property data provided by SilviScan (Shelbourne et al. 1997; Wu et al. 2007). Similarly, the estimation of genetic parameters based on NIR-predicted wood properties: cellulose in shining gum [Eucalyptus nitens (Dean and Maiden) Maiden] (Schimleck et al. 2004); cellulose, pulp yield, extractives and lignin content for Tasmanian blue gum (Eucalyptus globulus Labill.) (Raymond et al. 2001; Raymond and Schimleck 2002; Poke and Raymond 2006); and lignin, cellulose, hemicellulose, extractive content, pulp yield, and lignin monomer composition for maritime pine (Pinus pinaster Ait.) (da Silva Perez et al. 2007) have also been reported.

While these technologies have been explored in several tree breeding programs, they have yet to be utilized in a loblolly pine breeding program. Such methods could be valuable tools for assessing various wood quality traits in progeny tests in P. taeda breeding populations across the Southern United States, and their utility will be largely based on their correlations with standard laboratory procedures established for directly measuring wood quality traits on samples obtained destructively. Moreover, these methods should capture genetic variation in surrogate wood quality traits in breeding populations. Heritability values and phenotypic variation should be high enough to be effective for indirect selection of wood quality traits.

Eckard et al. (2010) used acoustics to indirectly measure MOE and MOR of a loblolly pine clonal trial, and found that stress-wave speed had greater variation in the population than any other directly measured solid wood trait. These authors reported highly repeatable clone means $(0.85)$ for stress-wave speed and moderately high genetic correlations with laboratory-measured MOE. Similarly, Jacques et al. (2004) reported a strong genetic correlation between sound velocity and wood stiffness in a clonal study of hybrid larch (Larix x eurolepis H.). Isik et al. (2008) reported moderately high $(0.79)$ clone mean heritabilities for MFA in Pinus taeda measured by SilviScan. Considerable genetic variation was detected among full-sib families of the same species for chemical wood traits using the NIR method (Sykes et al. 2006).

To our knowledge, the work presented here is unique, in the sense that indirect measure of wood traits based on NIR prediction models developed from subsamples of three diallel progeny tests (Mora et al. 2009; Mora and Schimleck 2009) were used for analysis. The objectives considered in this study were to:

1. Evaluate two nondestructive testing techniques (NIR and acoustics) suggested by Mora et al. (2009) and Mora and Schimleck (2009) for rapid screening of loblolly pine progeny tests for surrogate wood quality traits;

2. Estimate correlations between nondestructive measures of wood traits and correlations with growth traits, and;

3. Estimate genetic variances and heritability values for selected wood traits: density, MFA, tracheid coarseness, MOE and tracheid wall thickness for the assessment of indirect selection in tree breeding.

\section{Material and methods}

\subsection{Genetic material and field experiments}

The trees examined in this study were obtained from three different diallel series. A 6-tree disconnected-half-diallel mating design (referred to in the following text as diallel) was used to mate 12 parents. For each diallel, 30 crosses (full-sib families) were produced. Progeny of crosses were field tested by members of the North Carolina State University Cooperative Tree Improvement Program between 1987 and 1992. Three diallel test series (each with four sites) were located in three regions of the south-eastern United States: central Georgia (GA), southwestern South Carolina (SC), and the Atlantic coast of North Carolina 
(NC). A randomized complete block design with 6-tree row plots was utilized. Progeny of a diallel were tested together (separate from other diallels) on four sites and replicated over six blocks at each site. Owing to logistic and budget constraints two of the four test sites for each diallel and three of the six blocks at each site were sampled. Sites and blocks with high survival and uniformity were preferred. The total number of trees measured on each diallel series were 459, 519, and 526 for GA, NC and SC regions, respectively. At the time of the data collection (in 2006) the ages of trees from the GA sites were 15 and 16 years, the NC sites were 18 and 19 years, and the SC sites were 14 and 15 years.

2.2 Sampling of trees, data collection and nondestructive prediction of wood properties

Relationships between surrogate wood traits analyzed in this study and wood traits based on standard procedures were previously explored by Mora et al. (2009) and by Mora and Schimleck (2009). Readers are advised to refer to these papers for details about development of prediction models, calibrations and correlations with the in vivo estimates.

\subsubsection{Standing-tree acoustics}

Tree acoustic velocity $\left(V_{\mathrm{ToF}} ; \mathrm{m} / \mathrm{s}\right)$, was calculated as the average of three consecutive time-of-flight (ToF), or acoustic transit times, readouts $(\mu \mathrm{s} / \mathrm{m})$ obtained on each tree with the Fakopp TreeSonic microsecond timer (Fakopp Enterprise, Ágfalva, Hungary). The probes were positioned on the same side of the stem, $1 \mathrm{~m}$ apart, at approximately $45^{\circ}$ with respect to the main axis of the trunk, centered around breast height $(1.4 \mathrm{~m})$ and always on the same aspect to minimize environmental variation.

Acoustic dynamic stiffness $\left(E_{\mathrm{D}}\right)$ of each tree was predicted using the expression:

$E_{\mathrm{D}}=K \times\left(\frac{V_{\mathrm{ToF}}}{\sqrt{\frac{1-v}{(1+v)(1-2 v)}}}\right)^{2} \times \rho\left\{\frac{0.4(M C-30)}{100+M C}\right\}$

where $v$ is the approximated Poisson ratio of green wood, $\rho$ is the green wood density $\left(\mathrm{kg} / \mathrm{m}^{3}\right), M C$ is the wood moisture content (\%), and $K=9.84 \mathrm{E}-10$ is a constant used to incorporate gravitational acceleration and conversion to GPa. The reader is referred to Mora et al. (2009) for further details.

\subsubsection{Tree sampling}

After recording the acoustic transit times, a subsample of 20 trees that encompassed the range of measured velocities were measured (diameter and height), felled, delimbed, and destructively sampled at each test site. From each tree, two 40-mm thick wood disks were extracted at breast height (1.4 $\mathrm{m}$ from the base). The disks were further processed to obtain samples for near infrared (NIR) analysis. In addition, 12-mm increment cores, used for wood property predictions, were collected at breast height from a set of 531 trees (also spanning the range of measured velocities) across the three diallels.

\subsubsection{Sample preparation}

From each of the destructively sampled disks, a $12.5 \mathrm{~mm} \times$ $12.5 \mathrm{~mm}$ bark-to-bark sample (including the pith) was obtained. The bark-to-bark samples and increment cores were divided at the pith, and one half was prepared for data collection. The selected half was dried at $50^{\circ} \mathrm{C}$ for 24 hours, glued into wood holders and sectioned along its longitudinal axis using a twin-blade saw, to produce a radial longitudinal strip approximately $2 \mathrm{~mm}$ thick from the center of each sample. The radial-longitudinal strips obtained for the 60 destructively sampled trees were used for SilviScan and NIR modeling, while the strips obtained from increment cores were used for NIR analysis only.

\subsubsection{SilviScan analysis}

Smaller radial strips, $2 \mathrm{~mm}$ tangentially $\times 7 \mathrm{~mm}$ longitudinally, were cut from the strips scanned for NIR analysis and used for air-dry density (hereafter referred to as density) $\left(\mathrm{kg} / \mathrm{m}^{3}\right)$, microfibril angle (MFA; $\left.{ }^{\circ}\right)$, stiffness (MOE; GPa), tracheid coarseness $(\mu \mathrm{g} / \mathrm{m})$, and tracheid wall thickness $(\mu \mathrm{m})$ determination using the SilviScan-3 device (Paprican, Vancouver, BC, Canada).

The length of the SilviScan strips varied depending on the pith-to-bark length of the samples used for NIR analysis. Density was determined by X-ray densitometry at a resolution of $25 \mu \mathrm{m}$; MFA was measured by X-ray diffractometry at $5-\mathrm{mm}$ resolution using the variance method developed by Evans (1999); MOE estimates were obtained using a combination of X-ray densitometry and Xray diffractometry data collected at 5-mm resolution (Evans 2006); while tracheid coarseness and wall thickness were obtained by image analysis using the relationships given in Evans (1994). The SilviScan strips were not resin-extracted and the measurements were made in a conditioned atmosphere at $40 \%$ relative humidity $(\mathrm{RH})$ and $20^{\circ} \mathrm{C}$. All SilviScan measurements on 60 trees were used to develop NIR calibration models for the estimation of selected traits of all 531 trees for the three diallels.

\subsubsection{Near infrared spectroscopy}

NIR diffuse reflectance spectra were obtained in consecutive $10-\mathrm{mm}$ sections from the radial-longitudinal face of 
each strip using a FOSS NIR Systems (Laurel, MD, USA) Model 5000 spectrophotometer. The radial strips were held in a custom-made holder and a $5 \mathrm{~mm} \times 10 \mathrm{~mm}$ mask was used to ensure that a constant area was tested (Schimleck et al. 2001). NIR spectra were collected over the range of $1100-2498 \mathrm{~nm}$ with a resolution of $2 \mathrm{~nm}$, and the instrument reference used was a ceramic standard. The estimated instrumental noise, obtained by replicate measurements of the instrument's reference, was $1.2 \mathrm{E}-5 \mathrm{AU}$ (absorbance units). As with SilviScan, the strips were not resin-extracted and the measurements were made at $40 \%$ $\mathrm{RH}$ and $20^{\circ} \mathrm{C}$.

\subsubsection{NIR wood property calibrations}

The SilviScan data were averaged over 10-mm increments to match the NIR data, and calibrations for each wood property were developed using least-squares support vector machines (LS-SVM) as described by Mora and Schimleck (2009). LS-SVM is a sample-centric kernel regression method (Suykens et al. 2002) where the relationship between every sample is characterized by a kernel function (usually the Gaussian radial basis function) which maps the data into a higher dimensional feature space, which allows for the modeling of nonlinear systems (Cogdill and Dardenne 2004). The idea of using LS-SVM is to characterize the relationship between $\mathbf{X}$ (NIR spectra) and $\mathbf{Y}$ (wood property of interest) in a hyperspace where nonlinearity (observed for example for MFA and MOE with traditional NIR model fitting processes) does not represent a limitation for fitting the NIR calibration models. Once fitted, the LS-SVM calibrations were used to predict density, MFA, MOE, and tracheid coarseness and wall thickness of the strips obtained from the 531 increment cores extracted from the standing trees.

\subsection{Statistical analysis}

Variance components were estimated using the linear mixed model:

$$
\begin{aligned}
y_{i j k l m}= & \mu+T_{i}+T B_{i(j)}+G_{k}+G_{l}+T G_{k}+T G_{l}+S_{k l} \\
& +T S_{k l}+E_{i j k l m}
\end{aligned}
$$

Where $y_{i j k l m}$ is the $m$-th observation of the $i$-th site nested within $j$-th block for the $k l$-th cross; $\mu$ is the overall mean; $T_{i}$ is the fixed effect of the $i$-th site, $i=1 \ldots s ; T B_{i(j)}$ is the fixed effect of the $j$-th block within $i$-th site, $j=1 \ldots b ; G_{k}, G_{l}$ are the random general combining ability (GCA) effect of the $k$-th female or the $l$-th male, $N \sim\left(0, \sigma_{G}^{2}\right) ; T G_{k}, T G_{l}$ are the random interaction effect of female and males with site, $N \sim\left(0, \sigma_{G T}^{2}\right) ; S_{k l}$ is the random specific combining ability (SCA) effect of the $k l$-th $\operatorname{cross} N \sim\left(0, \sigma_{S}^{2}\right) ; T S_{k l}$ is the random SCA by site interaction effect $N \sim\left(0, \sigma_{S T}^{2}\right)$; $E_{i j k l m}$ is the random error term associated with the $m$-th tree $N \sim\left(0, \sigma_{E}^{2}\right)$. In matrix notation, Eq. 2 was expressed as

$\mathbf{y}=\mathbf{X} \boldsymbol{\beta}+\mathbf{Z} \boldsymbol{\gamma}+\varepsilon$

where $\mathbf{y}$ is the vector of individual observations, $\beta$ is the vector of fixed-effects parameters, $\gamma$ is the vector of random-effects parameters including general combining ability (GCA) for female and male, and specific combining ability (SCA), $\varepsilon$ represents an unknown random error vector, and $\mathbf{X}$ and $\mathbf{Z}$ represent the design matrix of fixed and random effects respectively. A major assumption of Eq. 3 is that the random effects $(\gamma)$ and the error term $(\varepsilon)$ are assumed to have normal distributions with 0 mean and variances given by:

$E\left(\begin{array}{l}\gamma \\ \boldsymbol{\varepsilon}\end{array}\right)=\left(\begin{array}{l}\mathbf{0} \\ \mathbf{0}\end{array}\right) ; \operatorname{Var}\left(\begin{array}{l}\gamma \\ \boldsymbol{\varepsilon}\end{array}\right)=\left(\begin{array}{ll}\mathbf{G} & \mathbf{0} \\ \mathbf{0} & \mathbf{R}\end{array}\right)$

Using variance components obtained from univariate mixed models analysis, narrow-sense heritability $\left(\mathrm{h}_{\mathrm{i}}^{2}\right)$, narrow-sense half-sib family mean heritability $\left(h_{\mathrm{HS}}^{2}\right)$, narrow-sense full-sib family mean heritability $\left(\mathrm{h}_{\mathrm{FS}}^{2}\right)$ and broad-sense full-sib family mean heritability $\left(\mathrm{H}_{\mathrm{FS}}^{2}\right)$ were calculated (Eq. 5 to 8 ) as:

$\mathrm{h}_{\mathrm{i}}^{2}=\frac{4 \sigma_{G}^{2}}{2 \sigma_{G}^{2}+\sigma_{S}^{2}+2 \sigma_{G T}^{2}+\sigma_{S T}^{2}+\sigma_{E}^{2}}$

$\mathrm{h}_{\mathrm{HS}}^{2}=\frac{\sigma_{G}^{2}}{\frac{p \sigma_{G}^{2}}{p-1}+\frac{\sigma_{S}^{2}}{p-1}+\frac{p \sigma_{G T}^{2}}{t(p-1)}+\frac{\sigma_{S T}^{2}}{t(p-1)}+\frac{\sigma_{E}^{2}}{b n t(p-1)}}$

$\mathrm{h}_{\mathrm{FS}}^{2}=\frac{2 \sigma_{G}^{2}}{2 \sigma_{G}^{2}+\sigma_{S}^{2}+\frac{2 \sigma_{G T}^{2}}{t}+\frac{\sigma_{S T}^{2}}{t}+\frac{\sigma_{E}^{2}}{b n t}}$

$\mathrm{H}_{\mathrm{FS}}^{2}=\frac{2 \sigma_{G}^{2}+\sigma_{S}^{2}}{2 \sigma_{G}^{2}+\sigma_{S}^{2}+\frac{2 \sigma_{G T}^{2}}{t}+\frac{\sigma_{S T}^{2}}{t}+\frac{\sigma_{E}^{2}}{b n t}}$

where, $\sigma_{G}^{2}$ is genetic variance due to general combining ability (GCA), $\sigma_{S}^{2}$ is genetic variance due to specific combining ability (SCA), $\sigma_{G T}^{2}$ is GCA by test interaction variance, $\sigma_{S T}^{2}$ is SCA by test site interaction variance, $\sigma_{E}^{2}$ is the error variance, $p$ is number of parents in the diallel set, $t$ is the number of test sites, $b$ is number of blocks at each test site, and $n$ is the number of trees within each block for each cross. Approximate standard errors were estimated using the Delta method (Lynch and Walsh 1998) and genetic parameters using the ASReml software (Gilmour et al. 2002). In order to compare phenotypic variance of traits with different units, coefficients of phenotypic variances of traits were 
calculated as $\mathrm{CV} \%=\sqrt{2 \sigma_{G}^{2}+\sigma_{S}^{2}+2 \sigma_{G T}^{2}+\sigma_{S T}^{2}+\sigma_{E}^{2}} / \bar{X}$, where $\bar{X}$ is the trait mean. Product-moment correlations between all pairs of acoustic and NIR-predicted traits based on full-sib family means for three diallel test series were determined.

\section{Results}

\subsection{Comparisons of diallel series}

Considerable difference in density was observed between diallel tests (Table 1). Other NIR-predicted wood trait means were similar for the three diallel series. For example, mean MOE ranged from 9.4 to 10.2 GPa for three diallels. Conversely, standing-tree acoustic velocity $\left(V_{\mathrm{ToF}}\right)$ and derived acoustic dynamic stiffness $\left(E_{\mathrm{D}}\right)$ varied among the diallel series, with $V_{\text {ToF }}$ ranging from 268 to $311 \mathrm{~m} / \mathrm{s}$ and $E_{\mathrm{D}}$ from 5.0 to $7.0 \mathrm{GPa}$. The differences between diallel tests for density, acoustic predicted $E_{\mathrm{D}}$ and $V_{\mathrm{ToF}}$ could be attributed to different growth rates and different ages of diallels at the time of sampling.

\subsection{Correlations between predicted wood traits}

Correlations based on full-sib family means between traits measured by the two nondestructive methods varied among traits and diallel series (Table 2). For example, MOE and acoustic dynamic stiffness had positive correlations, but the magnitude of the coefficients varied from $r=0.52$ (SC diallel) to $r=0.76$ ( $\mathrm{NC}$ diallel). Correlations between density, tracheid coarseness and tracheid wall thickness were all positive and high, exceeding $r=0.65$ in the three diallels tests. While density and MOE (stiffness) had moderate correlations in all diallels $(r=0.35$ to $r=0.60)$, the coefficients between density and acoustic dynamic stiffness $\left(E_{\mathrm{D}}\right)$ were weak $(r=0.02$ to $r=0.23)$. Density and acoustic velocity had weak and negative correlations (ranging from $r=-0.03$ to $r=-0.20$ ).

\subsection{Correlations between growth and predicted wood traits}

Predicted wood traits had zero or weak correlations with growth (DBH) in three diallels (Table 3). In fact, all the correlation coefficients of predicted wood traits with DBH were not significantly different from zero, except acoustic velocity $V_{\mathrm{ToF}}(r=-0.38)$ and MFA $(r=-0.50)$ in the GA diallel. The correlation between $V_{\mathrm{ToF}}$ and DBH was only marginally significant. Genetic correlations between traits were not estimated in this study due to small sample size (number of parents and progeny per parent). For reliable estimates, these parameters require a large number of parents and progeny per parent (Falconer and Mackay 1996).

\subsection{Variance components and heritability}

Variance components, their standard errors, $t$-values for variances and heritability estimates for acoustic and NIR predicted wood quality traits are given in Table 4 . Percent of variance components over total variance is presented in Appendix Table 6. The approximate $t$-values estimated for general combining ability variances (GCA) indicate that genetic variances for the acoustic-based wood traits were significant in all diallels. On the other hand, the significance levels of GCA variance for NIR-based traits varied depending on the trait and diallel analyzed. GCA variance for density was highly significant in all diallels; however, GCA variance for MFA was not significant in any diallel. The major reason for this could be the different sample size (number of trees assessed) used for acoustic versus NIR methods. For acoustics-based traits, the number of trees assessed ranged from 459 to 526, while for NIR predicted traits the sample size was much smaller (156 to 188 trees). GCA by site interaction variances were either zero or nonsignificant for all traits, suggesting that parental rankings
Table 1 Means and one standard error of means (SE) of the traits studied

Sample sizes for acoustic velocity and dynamic stiffness ranged from 459 to 520 . Sample sizes for height and DBH were 459 for GA and 519 for $\mathrm{NC}$ and 526 for SC. Sample sizes for NIR traits were 156 for GA, 186 for $\mathrm{NC}$ and 188 for SC

\begin{tabular}{|c|c|c|c|c|c|c|c|c|}
\hline \multirow[t]{2}{*}{ Traits (unit) } & \multicolumn{2}{|c|}{ Overall } & \multicolumn{2}{|c|}{ GA diallel } & \multicolumn{2}{|c|}{$\mathrm{NC}$ diallel } & \multicolumn{2}{|c|}{$\mathrm{SC}$ diallel } \\
\hline & Mean & SE & Mean & SE & Mean & SE & Mean & SE \\
\hline DBH (cm) & 21.5 & $(0.11)$ & 18.5 & $(0.11)$ & 22.8 & $(0.26)$ & 23.5 & $(0.14)$ \\
\hline Height (m) & 18.2 & $(0.09)$ & 14.9 & $(0.07)$ & 19.2 & $(0.13)$ & 20.7 & $(0.06)$ \\
\hline Acoustic velocity $(\mathrm{m} / \mathrm{s})$ & 283 & $(1.05)$ & 311 & $(2.21)$ & 268 & $(1.38)$ & 273 & $(1.20)$ \\
\hline Dynamic stiffness (GPa) & 6.2 & $(0.04)$ & 5.0 & $(0.06)$ & 7.0 & $(0.06)$ & 6.4 & $(0.05)$ \\
\hline NIR coarseness $(\mu \mathrm{g} / \mathrm{m})$ & 503 & $(1.35)$ & 510 & $(2.02)$ & 489 & $(2.79)$ & 510 & $(1.59)$ \\
\hline NIR cell wall $(\mu \mathrm{m})$ & 3.0 & $(0.01)$ & 2.9 & $(0.01)$ & 3.1 & $(0.02)$ & 3.0 & $(0.01)$ \\
\hline NIR density $\left(\mathrm{kg} / \mathrm{m}^{3}\right)$ & 510 & $(2.12)$ & 486 & (3.13) & 542 & $(3.71)$ & 499 & $(2.64)$ \\
\hline NIR MFA $\left(^{\circ}\right)$ & 24.8 & $(0.12)$ & 25.7 & $(0.23)$ & 25.3 & $(0.20)$ & 23.7 & $(0.19)$ \\
\hline NIR MOE (GPa) & 9.7 & $(0.07)$ & 9.4 & $(0.11)$ & 9.5 & $(0.13)$ & 10.2 & $(0.09)$ \\
\hline
\end{tabular}


Table 2 Product-moment correlation coefficients $(r)$ among wood quality traits measured by acoustics and NIR for the three diallel test series. Correlations are based on full-sib family means. Probability values $\left(H_{0}: r=0\right)$ are given in parenthesis. Coefficients with a probability $\leq 0.05$ are not significantly different from zero

\begin{tabular}{|c|c|c|c|c|c|c|}
\hline & Acoustic velocity & Dynamic stiffness & NIR density & NIR coarseness & NIR MFA & NIR MOE \\
\hline \multicolumn{7}{|l|}{ GA diallel } \\
\hline D. stiffness & $-0.99(<.001)$ & & & & & \\
\hline NIR density & $-0.03(0.865)$ & $0.02(0.920)$ & & & & \\
\hline NIR coarse. & $-0.18(0.364)$ & $0.17(0.376)$ & $\mathbf{0 . 8 2}(<.001)$ & & & \\
\hline NIR MFA & $\mathbf{0 . 7 0}(<.001)$ & $-\mathbf{0 . 6 9}(<.001)$ & $0.28(0.152)$ & $-0.02(0.906)$ & & \\
\hline NIR MOE & $-\mathbf{0 . 6 1}(0.001)$ & $\mathbf{0 . 5 8}(0.001)$ & $\mathbf{0 . 5 2}(0.004)$ & $0.74(<.001)$ & $-\mathbf{0 . 5 4}(0.003)$ & \\
\hline NIR wall & $-0.10(0.621)$ & $0.09(0.640)$ & $0.90(<.001)$ & $0.94(<.001)$ & $0.05(0.807)$ & $\mathbf{0 . 6 5}(<.001)$ \\
\hline \multicolumn{7}{|l|}{ NC diallel } \\
\hline D. stiffness & $-0.99(<.001)$ & & & & & \\
\hline NIR density & $-0.20(0.262)$ & $0.22(0.227)$ & & & & \\
\hline NIR coarse. & $-\mathbf{0 . 4 8}(0.005)$ & $\mathbf{0 . 5 5}(0.001)$ & $0.65(<.001)$ & & & \\
\hline NIR MFA & $0.85(<.001)$ & $-\mathbf{0 . 8 3}(<.001)$ & $-0.16(0.382)$ & $-\mathbf{0 . 4 6}(0.008)$ & & \\
\hline NIR MOE & $-0.71(<.001)$ & $0.76(<.001)$ & $\mathbf{0 . 6 0}(0.003)$ & $0.84(<.001)$ & $-\mathbf{0 . 7 3}(<.001)$ & \\
\hline NIR wall & $-\mathbf{0 . 4 3}(0.013)$ & $0.46(0.009)$ & $0.95(<.001)$ & $0.79(<.001)$ & $-\mathbf{0 . 3 8}(0.031)$ & $0.77(<.001)$ \\
\hline \multicolumn{7}{|l|}{ SC diallel } \\
\hline D. stiffness & $-0.99(<.001)$ & & & & & \\
\hline NIR density & $-0.18(0.341)$ & $0.23(0.219)$ & & & & \\
\hline NIR coarse. & $-0.08(0.654)$ & $0.14(0.459)$ & $0.69(<.001)$ & & & \\
\hline NIR MFA & $\mathbf{0 . 5 1}(0.004)$ & $-\mathbf{0 . 4 8}(0.007)$ & $\mathbf{0 . 3 8}(0.033)$ & $0.01(0.949)$ & & \\
\hline NIR MOE & $-\mathbf{0 . 4 8}(0.006)$ & $\mathbf{0 . 5 2}(0.003)$ & $0.35(0.053)$ & $0.65(<.001)$ & $-\mathbf{0 . 4 4}(0.013)$ & \\
\hline NIR wall & $-0.10(0.576)$ & $0.15(0.421)$ & $0.84(<.001)$ & $\mathbf{0 . 8 3}(<.001)$ & $0.12(0.513)$ & $0.48(0.006)$ \\
\hline
\end{tabular}

were stable across sites for both acoustic and NIR-predicted wood quality traits. Specific combining ability (SCA) effects (effects of full-sib families) were not significant or were zero for most traits.

Narrow-sense individual tree heritability values were generally high $(0.30)$ for the traits analyzed (Table 5), ranging from $h_{i}^{2}=0.14$ (coarseness in SC diallel) to $h_{i}^{2}=$ 0.92 (density in NC diallel). However, large differences were observed for the same traits across three diallels. For example, $h_{i}^{2}$ for acoustic velocity was high $(0.76)$ in the GA diallel compared to $h_{i}^{2}=0.38$ and $h_{i}^{2}=0.30$ found in the $\mathrm{NC}$ and SC diallels respectively. Density had the highest heritability estimates for the traits determined by NIR in the three diallels series. Individual-tree narrow-sense heritability values were associated with high standard errors $(\sim 0.20)$, ranging from 0.13 to 0.26 .

Half-sib family mean heritability values were mostly high ( $>0.80$ ), with generally smaller standard errors compared to individual-tree heritability estimates (Table 5). Acoustic-predicted traits had clearly greater half-sib family mean heritabilities and smaller standard errors compared to NIR-predicted wood traits, mainly due to different sample sizes. For example, acoustic dynamic stiffness half-sib family heritability ranged from 0.81 to 0.87 in three diallels, while the half-sib family mean heritability for NIR-predicted MOE ranged from 0.64 to 0.83. Full-sib
Table 3 Product-moment correlation coefficients of wood quality traits with diameter at breast height (DBH) based on full-sib family means in three diallel test series. Probability levels $\left(H_{0}: r=0\right)$ of correlation coefficients are given in parenthesis. Coefficients with a probability value $\leq 0.05$ are not significantly different from zero

\begin{tabular}{|c|c|c|c|c|c|c|c|}
\hline Diallel series & Acoustic velocity & Dynamic stiffness & NIR density & NIR coarseness & NIR MFA & NIR MOE & NIR cell wall \\
\hline $\mathrm{GA}(N=28)$ & $-\mathbf{0 . 3 8}(0.049)$ & $0.36(0.060)$ & $-0.09(0.651)$ & $0.16(0.417)$ & $-\mathbf{0 . 5 0}(0.006)$ & $0.35(0.066)$ & $0.06(0.776)$ \\
\hline $\mathrm{NC}(N=32)$ & $-0.10(0.577)$ & $0.14(0.458)$ & $0.15(0.417)$ & $0.27(0.128)$ & $-0.08(0.660)$ & $0.29(0.106)$ & $0.20(0.266)$ \\
\hline $\mathrm{SC}(N=31)$ & $-0.13(0.477)$ & $0.13(0.480)$ & $0.12(0.529)$ & $0.19(0.311)$ & $-0.08(0.685)$ & $0.34(0.062)$ & $0.11(0.543)$ \\
\hline
\end{tabular}

$N=$ number of family means, including the checklots 
Table 4 Variance components and their standard errors (SE) for the wood traits measured by the acoustic and NIR methods in the three diallel tests. Ratios of general combining ability (GCA) variance estimate to its standard error $(\mathrm{GCA} / \mathrm{SE}) \geq 1.8$ are significantly different from zero (bold faced) based on likelihood ratio tests

GCA, general combining ability; SCA, specific combining ability; GE, GCA by environment interaction; $t, t$-value obtained as GCA/SE

\begin{tabular}{|c|c|c|c|c|c|c|c|c|c|}
\hline & GCA & $\mathrm{SE}$ & $t$ & SCA & $\mathrm{SE}$ & GE & SE & Error & SE \\
\hline Trait & \multicolumn{9}{|c|}{ GA diallel } \\
\hline Acoustic velocity & 288 & 144 & 2.0 & 0 & - & 64 & 40 & 816 & 57 \\
\hline D. stiffness & 0.29 & 0.13 & 2.2 & 0 & - & 0.02 & 0.02 & 0.73 & 0.05 \\
\hline NIR density & 201 & 102 & 2.0 & 0 & - & 0 & - & 810 & 100 \\
\hline NIR coarseness & 90 & 48 & 1.9 & 0 & - & 0 & - & 465 & 57 \\
\hline NIR MFA & 0.51 & 0.45 & 1.1 & 0.83 & 0.68 & 0.08 & 0.23 & 4.9 & 0.68 \\
\hline NIR MOE & 0.09 & 0.10 & 0.9 & 0.20 & 0.15 & 0.02 & 0.05 & 0.97 & 0.14 \\
\hline \multirow[t]{2}{*}{ NIR cell wall } & 0.004 & 0.002 & 2.0 & 0.0003 & 0.002 & 0.001 & 0.001 & 0.03 & 0.01 \\
\hline & \multicolumn{9}{|c|}{ NC diallel } \\
\hline Acoustic velocity & 73 & 36 & 2.0 & 2.6 & 21 & 0 & - & 579 & 39 \\
\hline D. stiffness & 0.17 & 0.08 & 2.1 & 0 & - & 0 & - & 1.3 & 0.1 \\
\hline NIR density & 593 & 278 & 2.1 & 0 & - & 0 & - & 1407 & 156 \\
\hline NIR coarseness & 136 & 72 & 1.9 & 0 & - & 0 & - & 825 & 92 \\
\hline NIR MFA & 0.34 & 0.25 & 1.4 & 0 & - & 0 & - & 6.6 & 0.7 \\
\hline NIR MOE & 0.30 & 0.17 & 1.8 & 0 & - & 0 & - & 2.3 & 0.3 \\
\hline \multirow[t]{2}{*}{ NIR cell wall } & 0.016 & 0.008 & 2.0 & 0 & - & 0 & - & 0.05 & 0.01 \\
\hline & \multicolumn{9}{|c|}{ SC diallel } \\
\hline Acoustic velocity & 53 & 28 & 1.9 & 5.2 & 19 & 0 & - & 598 & 40 \\
\hline D. stiffness & 0.1 & 0.05 & 2.0 & 0 & - & 0 & - & 1.2 & 0.07 \\
\hline NIR density & 167 & 91 & 1.8 & 0 & - & 5 & 36 & 982 & 112 \\
\hline NIR coarseness & 17 & 23 & 0.7 & 0 & - & 31 & 26 & 377 & 43 \\
\hline NIR MFA & 0.45 & 0.31 & 1.5 & 0 & - & 0.05 & 0.19 & 5.4 & 0.62 \\
\hline NIR MOE & 0.10 & 0.08 & 1.3 & 0 & - & 0.05 & 0.06 & 1.3 & 0.1 \\
\hline NIR cell wall & 0.002 & 0.002 & 1.0 & 0 & - & 0.002 & 0.002 & 0.03 & 0.003 \\
\hline
\end{tabular}

family heritability values were slightly smaller than half-sib family heritability values for all traits and in all three diallels, mainly due to zero specific combining ability variance.

\section{Discussion}

Tree breeders have long recognized the effects and the importance of wood quality traits such as specific gravity, stiffness, and microfibril angle on the quality of end products (Zobel and van Buijtenen 1989). The high cost associated with the assessment of wood quality traits on a large scale has been a major obstacle for application in tree breeding. In this study, we estimated genetic parameters for various wood quality traits assessed by indirect methods (Mora et al. 2009; Mora and Schimleck 2009) for use in tree breeding programs.

Wood density is considered the most important wood quality trait, as it impacts structural wood quality, wood strength and pulp/paper properties (Megraw 1985; Zobel and van Buijtenen 1989) and it was observed to be highly correlated with tracheid coarseness and wall thickness, while relationships with $\mathrm{MOE}$, and particularly $E_{\mathrm{D}}$, were weaker. These correlation values reflect the fact that $E_{\mathrm{D}}$ depends on the green density of the outerwood portion of the trunks, and not on a weighted measure of air-dry density at breast height.

We observed significant differences between two indirect stiffness measurements (MOE and $E_{\mathrm{D}}$ ); however, this is not surprising, as MOE represents a cross-sectional weighted measure of wood stiffness at breast height $(1.4 \mathrm{~m}$ above ground), while $E_{\mathrm{D}}$ is a measure of stiffness in a column of outerwood, 2-3 cm thick and approximately $1 \mathrm{~m}$ long, centered around DBH (Auty and Achim 2008). In addition, MOE and $E_{\mathrm{D}}$ are predicted using different wood properties. While MOE estimates are based on NIR calibration models obtained from SilviScan measurements, using air-dry density and the amplitude of the azimuthal X-ray diffraction intensity profile of the sample, $E_{\mathrm{D}}$ uses green density, acoustic velocity and a correction factor (Eq. 1) to account for variations in moisture content of the wood (Mora et al. 2009).

In this study, weak and negative correlations were observed between density and acoustic velocity (Table 2). The results in this study are generally in agreement with results for a clonal loblolly pine progeny test (Eckard et al. 2010). The authors reported weak correlation $(r=0.08)$ between basic density (based on X-ray densitometry) and acoustic velocity measured using TreeSonic. When compared to standard laboratory procedures, better correlations 
Table 5 Heritability estimates and coefficients of phenotypic variances $(\mathrm{CV} \%)$ of surrogate wood quality traits measured by acoustics and NIR methods in the three diallel test series. Standard errors (SE) of the estimates are given in the parenthesis $\mathrm{h}_{\mathrm{i}}{ }^{2}$, narrow-sense heritability; $\mathrm{h}_{\mathrm{HS}}{ }^{2}$, narrow-sense half-sib family mean heritability; $\mathrm{h}_{\mathrm{FS}}^{2}$, narrowsense full-sib family mean heritability; $\mathrm{H}_{\mathrm{FS}}{ }^{2}$, broad-sense full-sib family means heritability $(*$ in some cases it was not estimated due to zero or non-significant GCA). CV\% is coefficient of phenotypic variance

\begin{tabular}{|c|c|c|c|c|c|c|c|c|c|}
\hline & $h_{i}^{2}$ & SE & $h_{H S}^{2}$ & SE & $h_{F S}^{2}$ & SE & $* H_{F S}^{2}$ & SE & $\mathrm{CV} \%$ \\
\hline Traits & \multicolumn{9}{|c|}{ GA diallel } \\
\hline Acoustic velocity & 0.76 & $(0.25)$ & 0.81 & $(0.07)$ & 0.83 & $(0.09)$ & - & - & 13 \\
\hline D. stiffness & 0.86 & $(0.23)$ & 0.88 & $(0.03)$ & 0.94 & $(0.04)$ & - & - & 23 \\
\hline NIR density & 0.66 & $(0.23)$ & 0.87 & $(0.02)$ & 0.75 & $(0.10)$ & - & - & 7 \\
\hline NIR coarseness & 0.56 & $(0.22)$ & 0.89 & $(0.02)$ & 0.68 & $(0.12)$ & - & - & 5 \\
\hline NIR MFA & 0.30 & $(0.26)$ & 0.68 & $(0.25)$ & 0.45 & $(0.33)$ & 0.82 & $(0.12)$ & 10 \\
\hline NIR MOE & 0.27 & $(0.26)$ & 0.64 & $(0.29)$ & 0.40 & $(0.33)$ & 0.81 & $(0.13)$ & 13 \\
\hline \multirow[t]{2}{*}{ NIR cell wall } & 0.41 & $(0.23)$ & 0.76 & $(0.17)$ & 0.72 & $(0.24)$ & 0.75 & $(0.17)$ & 7 \\
\hline & \multicolumn{9}{|c|}{$\mathrm{NC}$ diallel } \\
\hline Acoustic velocity & 0.38 & $(0.16)$ & 0.87 & $(0.03)$ & 0.74 & $(0.12)$ & 0.75 & $(0.11)$ & 10 \\
\hline D. stiffness & 0.42 & $(0.16)$ & 0.88 & $(0.02)$ & 0.82 & $(0.07)$ & - & - & 18 \\
\hline NIR density & 0.92 & $(0.24)$ & 0.89 & $(0.01)$ & 0.84 & $(0.07)$ & - & - & 9 \\
\hline NIR coarseness & 0.50 & $(0.21)$ & 0.85 & $(0.04)$ & 0.66 & $(0.12)$ & - & - & 7 \\
\hline NIR MFA & 0.19 & $(0.13)$ & 0.72 & $(0.11)$ & 0.38 & $(0.18)$ & - & - & 11 \\
\hline NIR MOE & 0.42 & $(0.19)$ & 0.83 & $(0.05)$ & 0.61 & $(0.14)$ & - & - & 18 \\
\hline \multirow[t]{2}{*}{ NIR cell wall } & 0.78 & $(0.24)$ & 0.88 & $(0.02)$ & 0.79 & $(0.08)$ & - & - & 9 \\
\hline & \multicolumn{9}{|c|}{ SC diallel } \\
\hline Acoustic velocity & 0.30 & $(0.13)$ & 0.85 & $(0.04)$ & 0.69 & $(0.14)$ & 0.73 & $(0.12)$ & 10 \\
\hline D. stiffness & 0.30 & $(0.13)$ & 0.79 & $(0.06)$ & 0.51 & $(0.13)$ & - & - & 18 \\
\hline NIR density & 0.50 & $(0.21)$ & 0.88 & $(0.10)$ & 0.84 & $(0.12)$ & - & - & 7 \\
\hline NIR coarseness & 0.14 & $(0.19)$ & 0.45 & $(0.44)$ & 0.39 & $(0.40)$ & - & - & 4 \\
\hline NIR MFA & 0.28 & $(0.17)$ & 0.82 & $(0.18)$ & 0.71 & $(0.20)$ & - & - & 11 \\
\hline NIR MOE & 0.25 & $(0.18)$ & 0.69 & $(0.25)$ & 0.61 & $(0.26)$ & - & - & 12 \\
\hline NIR cell wall & 0.20 & $(0.20)$ & 0.57 & $(0.34)$ & 0.50 & $(0.33)$ & - & - & 6 \\
\hline
\end{tabular}

between acoustics and MOE and MOR have been reported. Eckard et al. (2010) found moderately high correlations between acoustic velocity and static measures of MOE $(r=0.67)$ and MOR $(r=0.50)$, using laboratory procedures as described in the ASTM International (2009). Similarly, Auty and Achim (2008) reported high correlations between sound velocity and static MOE $(r=0.73)$ and MOR $(r=0.77)$ determined by the same standard.

Microfibril angle (MFA) is another important structural wood quality trait (Megraw 1985), and can be accurately measured by SilviScan (Evans and Ilic 2001). However, the method is prohibitively expensive for large sample sets (Isik et al. 2008). Using a 3-year clonal progeny test of Pinus radiata, strong clone mean correlations $(-0.87)$ were found between acoustic dynamic stiffness and MFA (Lindström et al. 2004). We also found moderate to high correlations between NIR-predicted MFA and acoustic velocity (Table 2). The results suggest that acoustic velocity can be used as a surrogate MFA measure in loblolly pine breeding programs.

Moderately high correlations $(r=-0.48$ to $r=-0.71)$ between acoustic velocity and MOE found in this study are encouraging for the rapid and large-scale assessment of MOE in loblolly pine breeding. Using a large number of loblolly pine clones, Eckard et al. (2010) reported moderately high clone mean $(0.67)$ and genetic correlation $(0.73)$ between acoustic velocity and laboratory-measured MOE. The reason for negative correlations in our study and positive correlations reported by Eckard et al. (2010) is that these authors expressed acoustic velocity in $\mathrm{km}^{2} / \mathrm{m}^{2}$ (which explains the positive sign of the correlation) while we expressed the acoustic velocity as $\mathrm{m} / \mathrm{s}$.

MOE and acoustic dynamic stiffness had positive correlations, but the magnitude of the coefficients varied from $r=0.52$ (SC diallel) to $r=0.76$ ( $\mathrm{NC}$ diallel). Interestingly, the correlation was weaker in the youngest diallel (GA) or when trees were smaller (SC). This may be an indication that as the amount of transition wood and (or) corewood increases, the relationship between $E_{\mathrm{D}}$ and $\mathrm{MOE}$ decreases, as suggested by Mora et al. (2009). Since trees in GA and SC diallels were considerably smaller in diameter than trees in $\mathrm{NC}$ diallel, the amount of corewood should be higher in GA and SC diallels.

The weak correlations observed between indirect wood quality traits and growth in this study are consistent with previously published results. In a radiata pine clonal study, Lindström et al. (2004) also reported a weak $(r=-0.12)$ correlation coefficient between acoustic velocity and diameter growth using clone means. Eckard et al. (2010) reported a weak $(r=-0.29)$ correlation between acoustic velocity and $\mathrm{DBH}$, using clone means from a cloned progeny test of loblolly pine. 
Employment of indirect/predicted wood quality traits in tree breeding programs will be determined mainly by their correlations with directly measured traits, cost effectiveness, heritability, and phenotypic variance. Variances estimated for indirect measured traits in this study are comparable with the results in the literature. For example, Isik et al. (2008) reported that full-sib family and clone within full-sib family effects together explained about $13 \%$ of the total phenotypic variance for MFA measured by SilviScan. In this study, the GCA effects alone explained 5 to $8 \%$ of phenotypic variance for NIR-predicted MFA. Eckard et al. (2010) reported high genetic variance components for MFA (35\%) and MOE $(43 \%)$ measured by laboratory tests. In the same study, they also reported $49 \%$ of the total variance in acoustic velocity due to genetic differences among clones. These percentages are higher partly because they represent total genetic variance since they analyzed clones, while the GCA effects (genetic differences among half-sib family means) theoretically account for $1 / 4$ of additive genetic variance (Falconer and Mackay 1996). In another study on loblolly pine (Sykes et al. 2006), GCA variance of juvenile wood properties of loblolly pine (ring 3 and ring 8 from the pith) explained 2\% to $10 \%$ of the total variance measured by wet chemistry.

Among the traits predicted by the acoustic and NIR methods, acoustic dynamic stiffness had the highest coefficient of phenotypic variance (\%) across three diallels (Table 5). NIR-predicted stiffness (MOE) also had high phenotypic variance. Acoustic velocity and MFA had relatively higher coefficients of phenotypic variance compared to the rest of the NIR-predicted traits. The magnitude of phenotypic variance is important from the point of view of tree improvement, because genetic gain is a function of phenotypic variance as well as heritability and selection intensity (Falconer and Mackay 1996).

Heritability is an important parameter in prediction of genetic gain estimates and developing breeding strategies (Falconer and Makay 1996). High narrow-sense individual tree and half-sib family mean heritability estimates in this study are encouraging for indirect assessment of wood quality traits and for use in loblolly pine breeding programs. Half-sib family mean heritability estimates were generally above 0.80 in three diallel test series, and are comparable with published results. Sykes et al. (2006) reported moderately high individual tree heritability for coarseness in both juvenile (0.39) and transition wood $(0.30)$ of $P$. taeda using wet chemistry methods. In the same study, full-sib and half-sib family mean heritability values for coarseness were moderate ( 0.62 to 0.72 ), whereas clonemean heritability of laboratory-measured density, static MOE and MOR ranged from 0.77 to 0.83 . In our study, half-sib family and full-sib family mean heritabilities for MOE ranged from 0.61 to 0.83 , except a low value of 0.40 in the GA diallel for full-sib family mean heritability.
Eckard et al. (2010) reported a clone mean heritability of 0.83 for stress wave velocity. The results in this study suggest that selection based on family means would be efficient for surrogate wood quality traits in tree improvement programs. An index selection of family and within family selection could provide considerable genetic gains for predicted wood quality traits in P. taeda.

Most of the individual-tree narrow-sense heritability values were associated with high standard errors, and in some cases they were as high as the estimates. This was not surprising, since the number of parents in each diallel series (12 parents) and particularly the sample size per parent were small (approximately 12 to 36 progeny per parent). It is known that heritability estimates from small disconnected diallels, such the ones used in this study, might fluctuate between theoretical limits because of random sampling of genetic effects caused by small sample size (Isik et al. 2005).

\section{Conclusions}

From the tree improvement point of view, these results are promising. Acoustics and NIR spectroscopy are efficient tools for the nondestructive measurement/prediction of various wood quality traits in tree breeding programs. Acoustics can be used to screen large number of trees (thousands) for indirect measurement of MFA and MOE for selection because the method is repeatable, as shown by high heritability estimates. This method is non-destructive, rapid, and cost-efficient. Though, reference values of green density and moisture content are required to appropriately adjust the estimates. NIR prediction models are also efficient methods for screening large number of trees for wood quality traits difficult to measure by direct methods. NIR models still require the collection of increment cores from trees, and determination of the properties of interest for fitting the calibration regressions. Thus, it is relatively more time-consuming compared to acoustics. However, a more detailed profile of the properties from pith to bark can be achieved with NIR models. In conclusion, surrogate wood traits measured by acoustics (dynamic wood stiffness and stress wave velocity) and predicted using calibration models based on NIR spectra had similar correlations and heritability estimates, based on direct laboratory assessments. Employment of such indirect methods should be considered in tree breeding programs that aim to improve wood quality.

Acknowledgement This research was supported by an USDA Forest Service Agenda 2020 grant. The authors gratefully acknowledge support from the Wood Quality Consortium of the University of Georgia, the USDA Forest Service Southern Research Station, and the North Carolina State University Cooperative Tree Improvement Program. The second author thanks Bioforest S.A. for the support to complete this work. Special thanks to Tyler Eckard for his help in data collection. 


\section{Appendix}

Table 6 Distributions (percent) of variance components over the total variance for indirect measured wood quality traits in three diallels

\begin{tabular}{|c|c|c|c|c|c|c|c|}
\hline GA diallel & Acoustic velocity & Dynamic stiffness & NIR density & NIR coarseness & NIR MFA & NIR MOE & NIR cell wall \\
\hline GCA & 25 & 28 & 20 & 16 & 8 & 7 & 11 \\
\hline SCA & 0 & 0 & 0 & 0 & 13 & 16 & 1 \\
\hline GE & 5 & 2 & 0 & 0 & 1 & 2 & 3 \\
\hline Error & 70 & 70 & 80 & 84 & 78 & 76 & 85 \\
\hline NC diallel & Acoustic velocity & Dynamic stiffness & NIR density & NIR coarseness & NIR MFA & NIR MOE & NIR cell wall \\
\hline GCA & 12 & 12 & 30 & 14 & 5 & 12 & 24 \\
\hline SCA & 0 & 0 & 0 & 0 & 0 & 0 & 0 \\
\hline GE & 0 & 0 & 0 & 0 & 0 & 0 & 0 \\
\hline Error & 88 & 88 & 70 & 86 & 95 & 88 & 76 \\
\hline SC diallel & Acoustic velocity & Dynamic stiffness & NIR density & NIR coarseness & NIR MFA & NIR MOE & NIR cell wall \\
\hline GCA & 8 & 8 & 14 & 4 & 8 & 7 & 6 \\
\hline SCA & 1 & 0 & 0 & 0 & 0 & 0 & 0 \\
\hline GE & 0 & 0 & 0 & 7 & 1 & 3 & 6 \\
\hline Error & 91 & 92 & 86 & 89 & 91 & 90 & 88 \\
\hline
\end{tabular}

$\mathrm{GCA}=$ general combining ability variance, $\mathrm{SCA}=$ specific combining ability variance, $\mathrm{GE}=\mathrm{GCA}$ by environment interaction variance

\section{References}

Atwood RA, White TL, Huber DA (2002) Genetic parameters and gains for growth and wood properties in Florida source loblolly pine in the southeastern United States. Can J For Res 32 (6): 1025-1038

Auty D, Achim A (2008) The relationship between standing tree acoustic assessment and timber quality in Scots pine and the practical implications for assessing timber quality from naturally regenerated stands. Forestry 81(4):475-487

ASTM International (2009) Annual book of ASTM standards, vol 4.10. ASTM International, Philadelphia, 808 pages

Byram TD, Mullin TJ, White TL, van Buijtenen JP (2005) The future of tree improvement in the southeastern United States: alternative visions for the next decade. South J Appl For 29(2):88-95

Chauhan S, Donnelly R, Huang CL et al (2006) Wood quality: multifaceted opportunities. In: Walker JC (ed.), Primary wood processing. Principles and practice, 2nd edition. Springer, Dordrecht, The Netherlands, pp 159-202

Cogdill RP, Dardenne P (2004) Least-squares support vector machines for chemometrics: an introduction and evaluation. J Near Infrared Spectrosc 12(2):93-100

da Silva Perez D, Guillemain A, Alazard P, Plomion C, Rozenberg P, Rodrigues JC, Alves A, Chantre G (2007) Improvement of Pinus pinaster Ait elite trees selection by combining near infrared spectroscopy and genetic tools. Holzforschung 61(6):611-622

Eckard TJ, Isik F, Bullock B, Li B, Gumpertz M (2010) Selection efficiency for solid wood traits in Pinus taeda using time-offlight acoustic and micro-drill resistance methods. For Sci 56 (3):233-241

Evans R (1994) Rapid measurement of the transverse dimensions of tracheids in radial wood sections from Pinus radiata. Holzforschung 48(2):168-172
Evans R (1999) A variance approach to the X-ray diffractometric estimation of microfibril angle in wood. Appita J 52(4):283-294

Evans R, Ilic J (2001) Rapid prediction of wood stiffness from microfibril angle and density. For Prod J 51:53-57

Evans R (2006) Wood stiffness by X-ray diffractometry. In: Stokke D, Groom L (eds) Characterization of the cellulosic cell wall. Blackwell, Ames, pp 138-146

Falconer DS, Mackay TFC (1996) Introduction to quantitative genetics, 4th edn. Longman Group Ltd., Harlow

Gapare WJ, Ivković M, Baltunis BS, Matheson CA, Wu HX (2010) Genetic stability of wood density and diameter in Pinus radiata D. Don plantation estate across Australia. Tree Gen Genom 6:113-125

Gilmour AR, Gogel BJ, Cullis BR, Welham SJ, Thomson R (2002) ASREML User Guide, Release 1.0. VSN International Ltd, Hemel Hempstead, 267 pages

Isik F, Li B (2003) Rapid assessment of wood density of live trees using the resistograph for selection in tree improvement programs. Can J For Res 33:2426-2435

Isik F, Boos DD, Li B (2005) The distribution of genetic parameter estimates and confidence intervals from small disconnected diallels. Theor Appl Genet 110:1436-2243

Isik F, Gumpertz M, Li B, Goldfarb B, Sun X (2008) Analysis of cellulose microfibril angle (MFA) using a linear mixed model in Pinus taeda clones. Can J For Res 38:1676-1689

Jacques D, Marchal M, Curnel Y (2004) Relative efficiency of alternative methods to evaluate wood stiffness in the frame of hybrid larch (Larix x eurolepis Henry) clonal selection. Ann Forest Sci 61:35-43

Kelley SS, Rials TG, Snell R, Groom LH, Sluiter A (2004) Use of near infrared spectroscopy to measure the chemical and mechanical properties of solid wood. Wood Sci Technol 38:257-276

Kumar S, Jayawickrama JS, Lee J, Lausberg M (2002) Direct and indirect measures of stiffness and strength show high heritability 
in a wind-pollinated radiata pine progeny test in New Zealand. Silvae Genet 51(5-6):256-261

Li B, McKeand S, Weir R (1999a) Tree improvement and sustainable forestry - impact of two cycles of loblolly pine breeding in the U.S.A. For Genet 6(4):229-234

Li B, McKeand SE, Weir RJ (1999b) Impact of forest genetics on sustainable forestry - results from two cycles of loblolly pine breeding in the U.S. J Sustain For 10(1-2):79-85

Lindström H, Harris P, Sorensson CT, Evans R (2004) Stiffness and wood variation of 3-year old Pinus radiata clones. Wood Sci Technol 38:579-597

Lynch M, Walsh B (1998) Genetics and analysis of quantitative traits. Sinauer Associates, Inc., Sunderland, MA, USA

Megraw RA (1985) Wood quality factors in loblolly pine. The influence of tree age, position in tree, and cultural practice on wood specific gravity, fiber length and fibril angle. Tappi Press, Norcross, GA, USA

Mora CR, Schimleck LR, Isik F, Mahon J Jr, Clark A III, Daniels R (2009) Relationships between acoustic variables and different measures of stiffness in standing Pinus taeda trees. Can J For Res 39(8):1421-1429

Mora CR, Schimleck LR (2009) Kernel regression methods for the prediction of wood properties of Pinus taeda using near infrared (NIR) spectroscopy. Wood Sci Technol, doi:10.1007/s00226009-0299-5

Poke FS, Raymond CA (2006) Predicting extractives, lignin, and cellulose contents using near infrared spectroscopy on solid wood in Eucalyptus. J Wood Chem Technol 26(2):187-199

Raymond CA, Schimleck LR, Muneri A, Michell AJ (2001) Genetic parameters and genotype-by-environment interactions for pulp yield and pulp productivity in Eucalyptus globulus predicted using near infrared reflectance analysis. For Genet 8(3):213-224
Raymond CA, Schimleck LR (2002) Development of near infrared reflectance analysis calibrations for estimating genetic parameters for cellulose content in Eucalyptus globulus. Can J For Res 32 (1):170-176

Schimleck L (2008) Near infrared spectroscopy: A rapid, nondestructive method for measuring wood properties and its application to tree breeding. New Zeal J Forest Sci 38:14-35

Schimleck LR, Kube PD, Raymond CA (2004) Genetic improvement of kraft pulp yield in Eucalyptus nitens using cellulose content determined by near infrared spectroscopy. Can J For Res 34 (11):2363-2370

Schimleck LR, Evans R, Illic J (2001) Estimation of Eucalyptus delegatensis wood properties by near infrared spectroscopy. Can J For Res 31(10):1671-1675

Shelbourne T, Evans R, Kibblewhite P, Low C (1997) Inheritance of tracheids transverse dimensions and wood density in radiata pine. Appita J 50(1):47-50, 67

Suykens JAK, Van Gestel T, De Brabanter J, De Moor B, Vandewalle J (2002) Least squares support vector machines. World Scientific Publishing, Singapore

Sykes R, Li B, Isik F, Kadla J, Chang H-m (2006) Genetic variation and genotype by environment interactions of juvenile wood chemical properties in Pinus taeda L. Ann Forest Sci 63(8):897-904

Wang X, Ross RJ, Erickson JR, Ligon JB (2000) Nondestructive evaluation of trees. Exp Tech 24(6):27-29

Wear DN, Greis JG (2002) Southern forest resource assessment, General Technical Report SRS 53. Asheville, NC. Southern Research Station

Wu H, Powell MB, Yang JL, Ivkovic M, McRae TA (2007) Efficiency of early selection for rotation-aged wood quality traits in radiata pine. Ann Forest Sci 64(1):1-9

Zobel BJ, van Buijtenen JP (1989) Wood variation its causes and control. Springer series in wood science. Springer, New York, 363 pages 